\title{
PENDAMPINGAN CERDAS BERMEDIA SOSIAL PADA ORANGTUA SISWA SD MUHAMMADIYAH LAWANG
}

\author{
Tutik Sulistyowati $^{1)}$, Luluk Dwi Kumalasari ${ }^{2)}$, Mochamad Aan Sugiharto ${ }^{3)}$ \\ Universitas Muhammadiyah Malang \\ tutiksulistyowati@umm.ac.id,lux_diva@yahoo.com, aansugiharto@umm.ac.id*
}

\begin{abstract}
The development of communication technology, especially mobile phones (HP), demands the role of parents in being able to assist children in using it. Elementary school's children nowadays are easy to open and use all the features available, so they have become accustomed to using social media. The tendency of children in social media still needs parental supervision and control, but not all parents are able to compensate for the intelligence of children in using mobile phones and existing features, especially Social Media. Therefore, efforts are needed to educate parents in assisting children in communicating through technology. This dedication is done in an effort to educate students' parents accompanying their sons to be smart in social media at Muhammadiyah Lawang Elementary School.
\end{abstract}

Keywords: Elementary school's; parents; social media; accompaniment
Submit
Diterima
28 Juni 2020
20 Juli 2020
Dipublikasikan
31 Juli 2020

DOI : https://doi.org/10.33503/pambudi.v4i01.838

\section{ANALISIS SITUASI}

Perkembangan teknologi saat ini semakin mudah dirasakan, salah satunya adalah gadget. Banyaknya gadget yang beredar di pasaran dengan berbagai pilihan model dan harga, membuat salah satu hasil dari perkembangan teknologi ini bisa dimiliki oleh semua kalangan masyarakat. Sebagai salah satu bentuk dari perkembangan teknologi, gadget menjadi benda yang tak bisa lepas dari kehidupan sehari-hari individu. Tua, muda, bahkan anak-anak saat ini sudah sangat akrab dengan gadget, bahkan bisa dikatakan jika justru anak-anaklah yang saat ini paling "akrab" dengan gadget.

Keakraban mereka dengan gagdet ini tidak jarang menimbulkan dampak negatif, karena berkurangnya jam untuk belajar sehingga terjadi penurunan nilai pelajaran. Realitas anak yang selalu berakrab ria dengan gadget dan menguasai cara penggunaannya ternyata sangat merisaukan berbagai pihak termasuk orang tua dan pihak sekolah. Di rumah anak sudah mulai jarang memanfaatkan waktunya di luar rumah, mereka terkurangi waktu berinteraksi dan bermain dengan teman seusianya, sehingga waktu belajar pun tersita. Sajian yang ada di gadget, terutama game bagi anak Sekolah Dasar merupakan menu favorit yang bisa dimainkan berjam-jam, mengasyikkan, membuat ketagihan, dan sangat menyita waktu untuk bermain di luar rumah dan belajar.

Kurangnya mereka berinteraksi dengan lingkungan ternyata juga membawa akibat akan perilaku dan sikap mereka yang cuek dan agak acuh, komunikasi sering tidak terarah, berani membantah dan melawan, tidak percaya diri untuk bisa bicara sesuai dengan konsep bahasa Indonesia yang benar dan anak-anak kurang memahami bagaimana seharusnya etika anak Indonesia diterapkan. Padahal anak adalah tunas, potensi, dan generasi penerus cita-cita perjuangan bangsa, anak memiliki peran strategis dan mempunyai ciri dan sifat khusus yang menjamin kelangsungan eksistensi Bangsa dan Negara pada masa depan. Oleh karena itu agar setiap anak kelak mampu memikul tanggung jawab 
tersebut, maka ia perlu mendapat kesempatan yang seluas-luasnya untuk tumbuh dan berkembang secara optimal, baik fisik, mental maupun sosial, dan berahklak mulia. Maka dari itu perlu dilakukan upaya perlindungan serta untuk mewujudkan kesejahteraan anak dengan memberikan jaminan terhadap pemenuhan hak-haknya serta adanya perlakuan tanpa diskriminasi. Termasuk di dalamnya adalah mendampingi mereka ketika mereka di rumah, terutama mendampingi anak ketika menggunakan gagdet.

Syifa (2019) Gadget dalam kehidupan anak-anak, terutama anak usia sekolah dasar sebenarnya memiliki dampak dan fungsi yang beragam. Dengan gadget yang saat ini semakin canggih, bisa membantu anak-anak untuk belajar, mendapatkan banyak informasi, juga memudahkan mereka untuk berkomunikasi dengan teman-temannya. Meskipun demikian, bagi anak-anak, gadget memiliki dampak negatif yang lebih banyak daripada dampak positif, termasuk terhadap perkembangan karakter anak (Puji Asmaul Chusna, 2017). Milana (2019) juga menyebutkan akibat perkembangan teknologi dan Gadget, membuat anak lebih cepat puas dengan pengetahuan yang dimiliki. Ramdhan Witarsa (2018) menyatakan bahwa gadget membuat anak menjadi pribadi yang antisosial, karena kesulitan melakukan interaksi dengan orang lain (Ariston, 2018).

Penelitian yang dilakukan oleh Dindin Syahyudin, secara fisik anak-anak yang kecanduan gadget akan malas beraktifitas dan mudah lelah. kecanduan pada gadget juga mengakibatkan bertambahnya pengeluaran uang untuk membeli pulsa, konsentrasi belajar berkurang dan bentuk kenakalan lainnya. Hal tersebut menunjukkan betapa Gadget memiliki sifat seperti 2 sisi mata uang, selain memiliki dampak positif, gadget juga memiliki potensi potensi menimbulkan dampak negatif pada anak. Di sinilah diperlukan peran orang tua, anak usia sekolah dasar perlu didampingi oleh orangtuanya dalam penggunaan gadget.
Mendampingi anak dalam menggunakan gadget di sini adalah lebih kepada edukasi dan kontrol dari orang tua kepada anak atas penggunaan gadget beserta beragam fitur dan aplikasi yang ada di dalamnya. Seperti diketahui, gadget memiliki banyak fitur dan aplikasi terutama sosial media yang bisa membuat penggunanya betah berlama-lama menghabiskan waktu. Youtube, facebook, instagram menjadi 3 dari sekian banyak aplikasi sosial media yang paling sering digunakan pada gadget. Permasalahannya saat ini adalah tidak semua orangtua paham betul dan akrab dengan fitur serta aplikasi di dalam gadget, terutama media sosial. Hal yang demikian ini, ternyata juga dirasakan oleh pihak wali murid di SD Muhammadiyah Lawang. Harapan untuk membentuk karakter anak Indonesia tadi dirasa belum berhasil secara maksimal melalui kegiatan-kegiatan yang diadakan sekolah saja tannpa peran dari wali murid selaku orang tua anak. Untuk itu, agar bisa mendampingi anak dengan optimal, para orangtua perlu melek teknologi.

Konsep melek teknologi yang dimaksud salah satunya adalah bagaimana kita bisa cerdas bermedia sosial, karena media sosial dengan berbagai macam jenis dan fungsinya yang disajikan sangat memanjakan penggunanya yang bisa dengan leluasa untuk memilih dan menggunakan aplikasi-aplikasi yang ditawarkan tersebut. Cerdas bermedia sosial yang dimaksud adalah bisa menguasai dan menggunakan sosial media dengan bijak sesuai dengan fungsi yang diharapkan seperti menyebarkan informasi yang bermanfaat. Dengan begitu, orang tua bisa mengimbangi kemampuan anak dalam bermedia sosial dan menularkan dan memberikan arahan kepada anak tentang bermedia sosial yang baik dan benar.

Untuk mengatasi persoalan di atas, pihak sekolah dan wali murid menginginkan adanya peran dari pihak luar yaitu dari pihak akademisi atau praktisi agar bisa terlibat juga, apakah melalui seminar, pelatihan dan kegiatan yang lain untuk mendampingi wali 
murid untuk cerdas bermedia agak bisa dengan kritis dan bijak mendampingi anakanaknya dalam bermedia sosial. Agar dengan pendampingan ini, anak-anak sedikit demi sedikit bisa merubah sikap dan perilakunya untuk bertanggung jawab dalam perilakunya dan berprestasi lagi dalam sekolahnya.

\section{METODE PELAKSANAAN}

Untuk menjawab permasalahan yang dihadapi oleh para orang tua siswa dan pihak sekolah yang merasa khawatir akan perkembangan anak dan menginginkan peran orang tua di rumah secara maksimal, maka dalam pengabdian ini ada beberapa tahap kegiatan. Namun untuk mempermudah pelaksanaan kegiatan, berikut ditunjukkan identifikasi masalah dan solusi yang ditawarkan:

Tabel 1. Identifikasi Masalah dan Solusi yang Ditawarkan

\begin{tabular}{|l|l|l|}
\hline NO. & $\begin{array}{l}\text { IDENTIFIKASI } \\
\text { MASALAH }\end{array}$ & $\begin{array}{l}\text { SOLUSI YANG } \\
\text { DITAWARKAN }\end{array}$ \\
\hline 1. & $\begin{array}{l}\text { Orang tua kurang } \\
\text { memahami akibat } \\
\text { anak menggunakan } \\
\text { dan membuka semua } \\
\text { fitur yang ada di hp. } \\
\text { orang tua tentang } \\
\text { akibat } \\
\text { menggunakan dan } \\
\text { membuka semua } \\
\text { fitur Hp bagi anak. }\end{array}$ & $\begin{array}{l}\text { Menjelaskan kepada } \\
\text { Orang tua kurang } \\
\text { memahami seberapa } \\
\text { banyak fitur yang } \\
\text { biasa digunakan } \\
\text { anak tuntang } \\
\text { berbagai macam } \\
\text { fitur yang bisa } \\
\text { digunakan untuk } \\
\text { bermedia sosial pad } \\
\text { anak. }\end{array}$ \\
\hline 3. & $\begin{array}{l}\text { Orang tua kurang } \\
\text { memahami } \\
\text { bagaimana anak bisa } \\
\text { menggunakan fitur } \\
\text { dalam Hp }\end{array}$ & $\begin{array}{l}\text { Menjelaskan kepada } \\
\text { orang tua tentang } \\
\text { bagaimana anak } \\
\text { menggunakan fitur } \\
\text { dalam Hp }\end{array}$ \\
\hline 4. & $\begin{array}{l}\text { Orang tua kurang } \\
\text { memahami peran } \\
\text { control sosial dalam } \\
\text { membentuk karakter } \\
\text { anak lewat media } \\
\text { sosial. }\end{array}$ & $\begin{array}{l}\text { Menjelaskan kepada } \\
\text { orangtua tentang } \\
\text { peran control sosial } \\
\text { sehingga mampu } \\
\text { membentuk } \\
\text { karakter anak lewat } \\
\text { media sosial. }\end{array}$ \\
\hline
\end{tabular}

Dalam hal ini mitra yaitu Sekolah Dasar Muhammadiyah Bedali Lawang dilibatkan secara penuh dan harus berpartisipasi secara aktif. Partisipasi mitra diantaranya adalah:

1. Menyediakan ruangan atau tempat untuk pelaksanaan seminar dan pelatihan.

2. Pengurus mengumumkan adanya pengabdian masyarakat internal ini kepada para wali murud dan memastikan wali murid bersedia berpartisipasi dalam rangkaian kegiatan pengabdian.

3. Peserta kegiatan harus berpartisipasi aktif terutama dalam proses pelatihan yang berorientasi pada penguatan life skill orang tua.

Sedang dalam pelaksanaan kegiatan pengabdian akan dilakukan dalam dua tahap yaitu tahap workshop dalam bentuk dialog interaktif antara orang tua siswa dengan tim pengabdi, serta pelatihan dan praktik cerdas bermedia antara orang tua dengan anak. Berikut ditunjukkan garis-garis besar rencana kegiatan.

\section{HASIL DAN PEMBAHASAN}

Seperti yang diketahui bahwa setiap faktor dari luar akan memberikan dampak bagi seseorang, termasuk dampak media sosial bagi anak usia SD. Dampak tersebut termasuk dampak sosial dan psikologis, yang mana terbagi menjadi positif dan negatif. Dengan memaparkan realita yang saat ini terjadi, tim pengabdian memberikan ulasan mendetail tentang realita yang saat ini dialami oleh orang tua terutama mereka yang saat ini memiliki anak usia Sekolah Dasar dan sudah familiar dengan gadget atau smartphone. Realita saat ini, banyak anak usia Sekolah Dasar yang lebih banyak menghasbiskan waktunya dengan bermain gadget daripada bermain dengan teman atau orang tua. Dipaparkan, bahwa setelah selesai belajar di sekolah, anak-anak akan langsung memegang gadget dan bermain dengan gadget tersebut yang menyuguhkan berbagai fitur game dan media sosial di dalamnya.

Jika dihitung, waktu yang dihabiskan oleh anak-anak untuk bermain dengan gadget jauh lebih banyak daripada waktu mereka 
bermain dan belajar bersama temantemannya. Dengan segala kecanggihannya, gadget memang menjadi media yang sangat efektif bagi anak untuk belajar banyak hal. Seperti belajar berhitung, membaca dan banyak hal lainnya yang bisa didapatkan dari fitur-fitur yang ada di gadget mereka. Misalnya dengan youtube mereka bisa belajar banyak hal seperti membaca, menghitung, bahkan membuat makanan ringan dari video yang ada di sana. Tetapi selain itu, ada dampak negatif yang mengiringinya.

Minimnya filter dan pantauan orang tua, terlebih dengan aplikasi youtube yang semua orang bisa bebas memposting video, maka akan berbahaya jika anak usia SD melihat video yang semestinya belum cocok mereka lihat. Seperti video yang mengandung unsur kekerasan atau video yang menggunakan bahasa kurang sopan atau justru cenderung terkesan bahasa jorok. Tentu hal tersebut sangat tidak layak untuk dikonsumsi oleh anak usia Sekolah Dasar. Maka, di sini Tim Pengabdian memberikan materi tentang hal tersebut yang dipaparkan oleh Luluk dwi Kumalasari, M.Si.

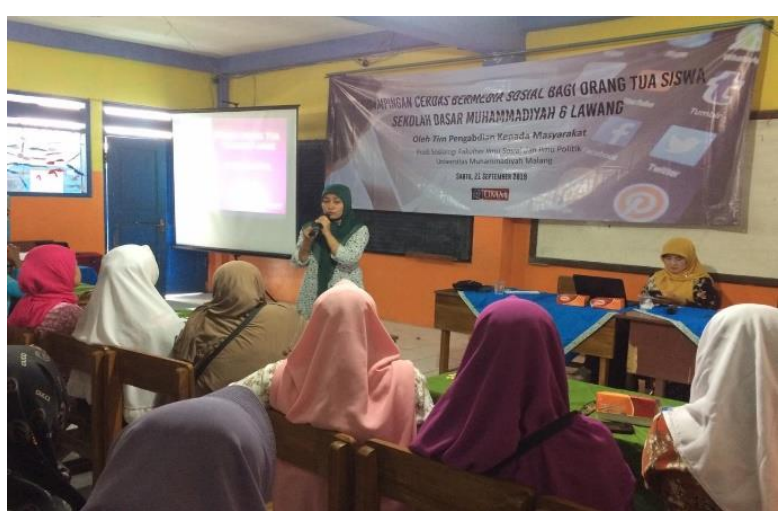

Gambar 1. Materi Dampak Media Sosial Bagi Anak Usia SD oleh Tim Pengabdian

Selanjutnya adalah materi tentang pentingnya peran orang tua dalam mendampingi anak di tengah pesatnya perkembangan teknologi dan revolusi industri 4.0. di sini, tim pengabdian memaparkan peran-peran yang harus dijalankan oleh orang tua terutama menhadapi anak milenial. Maka, sebelumnya perlu diberikan penjelasan terlebih dahulu kepada orangtua tentang apa yang dimaksud dengan anak milenial, bagaimana ciri-cirinya dan bagaimana pola pengasuhan yang paling tepat terhadap anak milenial.

Setelah mengetahui segala sesuatu tentang anak milenial, maka orang tua juga harus siap menjadi orang tua dari anak milenial. Banyak cara menjadi orang tua dari anak milenial, salah satunya adalah kemampuan untuk memahami potensi yang dimiliki oleh anak dan menfasilitasi anak agar potensi yang dimiliki oleh anak bisa berkembang dengan maksimal. Dengan kepakaran di sosiologi keluarga dan gender, materi tentang peran orang tua di era digital sangat tepat disampaikan oleh Dr. Tutik Sulistyowati, M.Si

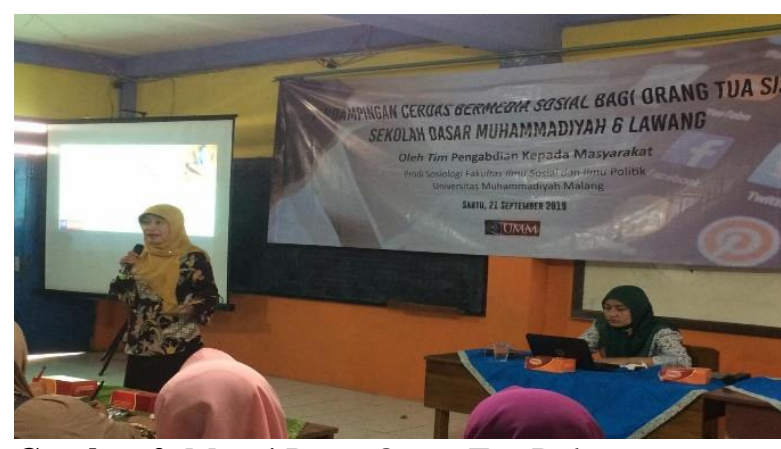

Gambar 2. Materi Peran Orang Tua Dalam Pendampingan Bersosial Media oleh Tim Pengabdian

Sesi terakhir adalah sesi tanya jawab yang dipandu oleh MC dan moderator dari pihak Sekolah Dasar Muhammadiyah Lawang. Setelah mendapatkan materi dari tim pengabdian, para wali murid yang hadir sangat antusias untuk bertanya. Pertanyaan mereka di antaranya terkait dengan pola asuh terhadap anak yang saat ini sangat dekat dengan gadget.

Wali murid juga mengeluhkan tentang bagaimana susahnya mengasuh anak yang sudah "kecanduan" gadget seperti mengajak mereka untuk berkomunikasi, bermain secara motorik dan bersenda gurau. Ada juga pertanyaan terkait dengan pola asuh dan cara bersikap kepada anak yang paling tepat terkait dengan kecenderungan hubungan sosial 
antara orang tua dan anak yang saat ini ditekankan untuk lebih melihat anak sebagai teman, tetapi karena hal tersebut banyak orang tua yang justru mengalami kerepotan karena dengan menerapkan pendekatan anak dan orang tua sebagai teman, justru dalam beberapa hal orang tua mengalami kesulitan jika ingin mendidik anak. Misalnya, anak menjadi sulit menurut terhadap perintah orang tua karena anak merasa bahwa tidak ada kewajiban untuk menurut kepada teman. Menanggapi pertanyaan dan realita seperti itu, tim pengabdian memberikan penjelasan tentang batasan-batasan yang harus dibuat secara tegas antara orang tua dan anak. Orang tua harus memberikan batasan yang tegas di awal tentang peran orang tua dan wewenang yang dimiliki oleh orang tua terhadap anak.

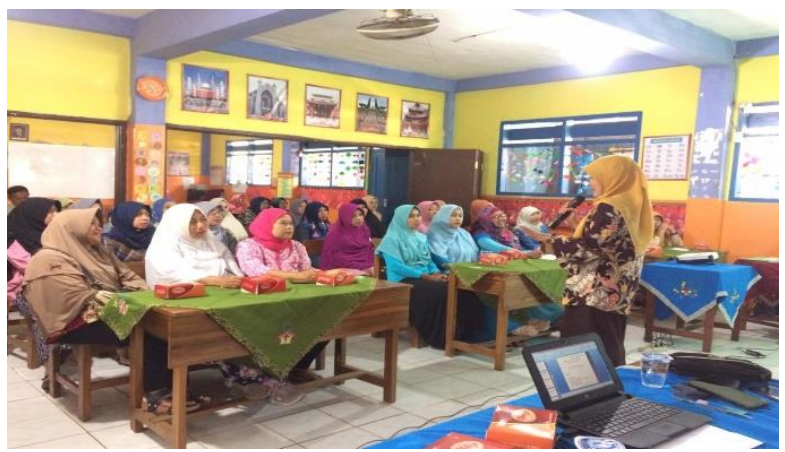

Gambar 3. Sesi tanya jawab antara wali murid dengan tim pengabdian

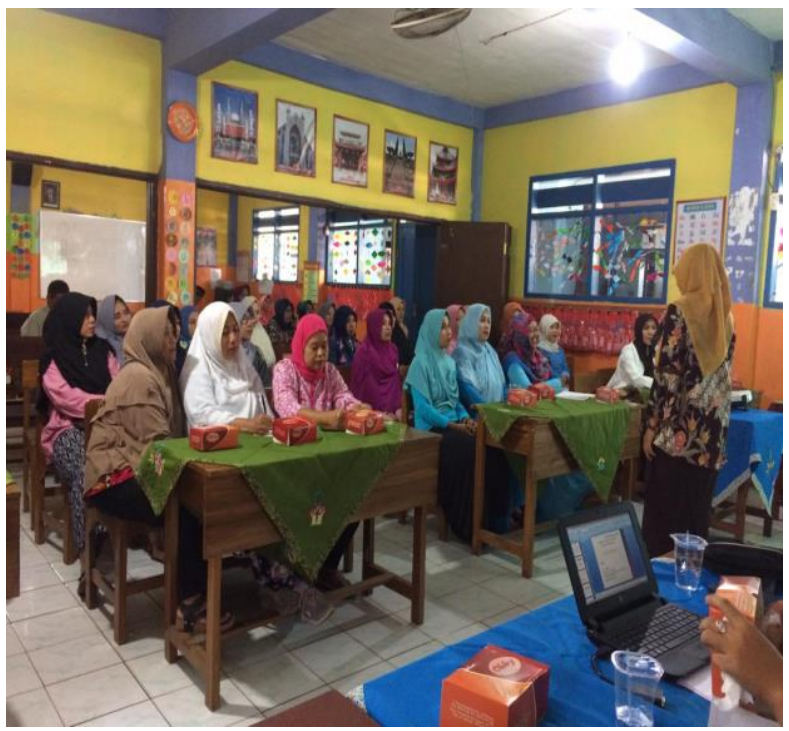

Gambar 4. Sesi tanya jawab antara wali murid dengan tim pengabdian

\section{KESIMPULAN}

Berdasarkan uraian hasil dan pembahasan dari kegiatan pengabdian ini, maka dapat diambil kesimpulan bahwa saat ini para orangtua terutama orangtua yang memiliki anak usia sekolah dasar menghadapi kenyataan bahwa anak mereka saat ini sudah akrab bahkan lebih akrab dengan gadget daripada dengan mereka. Akibat fenomena tersebut, orangtua mengalami kesulitan berinteraksi dengan anak mereka, terutama untuk anak yang "kecanduan" dengan gadget. Untuk itu, diperlukan pola asuh yang menyesuaikan dengan kebutuhan anak mereka, yang dalam pengabdian ini kami menyebutnya dengan "menjadi orangtua milenial".

\section{Ucapan Terima Kasih}

Kami mengucapkan banyak terima kasih kepada seluruh pihak yang terlibat dalam kegiatan pengabdian kepada masyarakat ini. Kepada pihak Sekolah Dasar Muhammadiyah Lawang kami sampaikan banyak terima kasih karena telah menerima kami dan membantu menyediakan tempat dan mengordinir para orangtua siswa untuk hadir dan berpartisipasi dalam program ini. Juga kami menyampaikan banyak terima kasih kepada para orangtua siswa yang bersedia meluangkan waktu untuk mengikuti kegiatan ini, karena kami sadar dan paham betul bahwa dengan mengikuti kegiatan ini, mereka telah mengorbankan waktu untuk bekerja mereka.

\section{DAFTAR PUSTAKA}

Ariston, Yummi. Dampak Penggunaan Gadget Bagi Perkembangan Sosial Anak Sekolah Dasar, Journal of Educational Review And Research, Vol. 1 No. 2, December 2018. Page: $86-91$.

Milana Abdillah Subarkah, Pengaruh Gadget Terhadap Perkembangan Anak, Jurnal Rausyan Fikr. Vol. 15 No.1 Maret 2019.

Puji Asmaul Chusna, Pengaruh Media Gadget Pada Perkembangan Karakter Anak, 
Jurnal Dinamika, Vol. 17, No. 2, November 2017.

Ramdhan Witarsa Dkk, Pengaruh

Penggunaan Gadget Terhadap

Kemampuan Interaksi Sosial Siswa

Sekolah Dasar, Jurnal PEDAGOGIK

Vol. VI, No. 1, Februari 2018.

Syahyudin, Dindin, Pengaruh Gadget

Terhadap Pola Interaksi Sosial Dan

Komunikasi Siswa, GUNAHUMAS,

Jurnal Kehumasan, Volume 2, Nomor

1, Edisi Agustus, Tahun 2019

Syifa, Layyinatus dkk, Dampak Penggunaan

Gadget terhadap Perkembangan

Psikologi pada Anak Sekolah Dasar,

Jurnal Ilmiah Sekolah Dasar Volume

3, Number 4 Tahun 2019, pp. 527-533. 